\title{
COMPARISON OF THE EFFICACY AND TOLERABILITY OF CHONDROITIN PLUS GLUCOSAMINE AND D-002 (BEESWAX ALCOHOLS) IN SUBJECTS WITH OSTEOARTHRITIS SYMPTOMS
}

\author{
Roberto Puente, ${ }^{1}$ José IIInait, ${ }^{1}$ Rosa Mas, ${ }^{2}$ Ernesto Lopez, ${ }^{1}$ Sarahí Mendoza, ${ }^{2}$ Daisy Carbajal, ${ }^{2}$ \\ Lilia Fernandez, ${ }^{2}$ Julio Fernández, ${ }^{2}$ Meilis Mesa, ${ }^{1}$ Pablo Reyes ${ }^{3}$ Dalmer Ruiz ${ }^{3}$
}

\begin{abstract}
Background/Aims: Osteoarthritis (OA), the commonest joint disorder, is a leading cause of disability. Symptomatic slow-acting drugs for OA (SYSADOA), particularly glucosamine plus chondroitin sulphate (GS/CS), are effective for symptom relief, protect joint cartilage and delay OA progression, with a good safety profile. D-002, a mixture of beeswax alcohols that inhibits both cyclooxygenase and 5-lipoxygenase activities, has been effective in experimental and clinical OA studies, showing also a chondroprotective effect.

Objectives: To compare the effects of D-002 and GS/SC administered for 12 weeks on OA symptoms. Methods: Participants were randomized to GS/CS (375/300 mg) or $50 \mathrm{mg}$ D-002 once daily for 12 weeks. Symptoms were assessed by the Western Ontario and McMaster Individual Osteoarthritis Index (WOMAC) and the Visual Analogy Scale (VAS) scores. The primary outcome was the reduction of the total WOMAC score. Secondary outcomes included WOMAC pain, stiffness and function scores, VAS score and rescue medication consumption.

Results: Of 60 randomized patients, 59 completed the study. D-002 and GS/SC reduced significantly total WOMAC score $(72.1 \%$ and $78.5 \%$, respectively), and pain, joint stiffness and physical function scores versus baseline. VAS scores decreased significantly with D-002 (76.6\%) and GS/SC (76.8\%). The reductions, significant from the second week, were enhanced over the trial. Rescue medications were consumed by 3/30 D-002 and 4/30 GS/SC patients. No differences between groups were found. Treatments were well tolerated.

Conclusions: D-002 (50 mg/day) administered for 12 weeks was safe and comparable to GS/SC for alleviating OA symptoms (pain, stiffness, and functional limitation) (RPCEC00000180).
\end{abstract}

Key words (MeSH terms): D-002, beeswax alcohols, chondroitin sulphate, glucosamine, osteoarthritis, WOMAC score, VAS score

\footnotetext{
1 Surgical Medical Research Centre (Havana, Cuba)

2 Centre of Natural Products, National Centre for Scientific Research (Havana, Cuba)

3 Software and Database Group, National Centre for Scientific Research (Havana, Cuba)

Correspondence to:

Dra Sarahí Mendoza, PhD.

Centre of Natural Products, National Centre for Scientific Research

198 street and 19, Cubanacan,

PO Box 6414, Havana, Cuba

Phone number: (537) 2714200

e.mail: clinica@enet.cu; sarahi.mendoza@cnic.edu.cu
}

Disclosure: No potential conflicts of financial interest relevant to this article were reported 


\section{Resumen}

Antecedentes: La osteoartritis (OA), el desorden articular más común es causa principal de discapacidad. Las drogas SYSADOA (Symptomatic slow-acting drugs for OA), particularmente la combinación glucosamina/condroitín sulfato (GS/CS), son efectivas en el alivio de los síntomas, protegen el cartílago articular y retrasan la progresión de la OA, con un buen perfil de seguridad. El D-002, una mezcla de alcoholes de la cera de abejas que inhibe la actividad de las enzimas ciclooxigenasa y 5- lipooxigenasa, ha sido efectivo en estudios experimentales y clínicos, mostrando también efectos condroprotectores.

Objetivo: Comparar los efectos de la administración de D-002 y el GS/SC durante 12 semanas sobre los síntomas de la OA.

Material y Métodos: Los pacientes recibieron aleatoriamente GS/CS (375/300 mg/d) o D-002 (50 mg/d) por 12 semanas. La evaluación de los síntomas se realizó a traves de las escalas WOMAC (Western Ontario and McMaster Individual Osteoarthritis Index) y la VAS (Visual Analogy Scale). La variable principal de eficacia fue la reducción de puntaje de la escala WOMAC. La variable secundaria incluyó los puntajes en los dominios dolor, rigidez y función física de la escala WOMAC, el puntaje de la escala VAS y el consumo de la medicación de rescate.

Resultados: De los 60 pacientes incluidos, 59 finalizaron el estudio. El D-002 y la combinación GS/SC redujeron significativamente el puntaje de la escala WOMAC (72.1\% y $78.5 \%$, respectivamente) y los puntajes de los dominios dolor, rigidez y función física versus el nivel basal. El puntaje de la escala VAS disminuyó significativamente en $76.6 \%$ en el grupo D-002 y $76.8 \%$ en el grupo GS/SC. Las reducciones significativas alcanzadas desde la segunda semana se incrementaron en el transacurso del estudio.Utilizaron medicación de rescate 3/30 del grupo D-002 y 4/30 pacientes de los que recibieron la combinación GS/SC. No se encontraron diferencias significativas entre grupos. La tolerancia al tratamiento fue buena. Conclusiones: El tratamiento con D-002 (50 mg/día) durante 12 semanas fue seguro y comparable al grupo que recibió GS/SC en el alivio de los síntomas de la OA (dolor, rigidez y limitación funcional) (RPCEC00000180).

Palabras Claves: D-002, alcoholes de la cera de abeja, chondroitin sulfato, glucosamina, osteoartritis, puntaje WOMAC, Puntaje VAS.

\section{Introduction}

Osteoarthritis (OA), the commonest musculoskeletal disorder, is a leading casue of disability worldwide, mainly in the elderly. According to the increasing life expectancy, OA is expected to become the fourth leading cause of disability by 2020. ${ }^{1-4}$ OA is a progressive, painful and degenerative joint disease that affects every single tissue in the joint, characterized by localized cartilage loss, remodelling of adjacent bone and linked inflammation. ${ }^{2-5}$

OA management requires non-pharmacological and pharmacological approaches. ${ }^{6-13}$ While nonpharmacological is the pivotal treatment, ${ }^{8}$ it alone frequently is not enough for symptom relief and stopping OA progression. In turn, pharmacotherapy focuses on symptom relief with analgesics for pain, such as paracetamol, and non-steroidal anti-inflammatory drugs (NSAIDs) to treat both pain and associated inflammation. Analgesics and NSAIDs, however, are not only unable to solve the causal pathological process on the joint, but NSAIDs can produce gastrointestinal and cardiovascular adverse effects (AE), and paracetamol may cause hepatotoxicity. ${ }^{9-13}$ In light of these sounds, there is updated interest in the search for safer alternatives to long-term manage $O A$. Symptomatic slow-acting drugs for OA (SYSA- 
DOA) (glucosamine sulfate, glucosamine hydrochloride, chondroitin sulfate, hyaluronic acid, avocado soybean unsaponifiables, diacerein), second-line drugs for $\mathrm{OA}$, improve the symptoms, decrease cartilage injury and are safer than NSAIDs and paracetamol for continuous or recurrent use. ${ }^{12}$ The discrepancies in the acceptance of SYSADOA in different OA guidelines, a matter influenced by many factors, may explain why their availability and prescription can considerably vary in different countries, so that a call for OA guidelines harmonization seems to be convenient. ${ }^{12}$

Various clinical trials have been conducted with SYSADOA. In particular, combined therapy with glucosamine (GS) plus chondroitin sulphate (CS) (GS/CS), has shown to produce symptom relief, protect joint cartilage and delay OA progression, with a good safety profile. ${ }^{14-18}$ A review of randomized trials, albeit most reported of low quality, concluded that short-term administration of chondroitin (alone or with glucosamine) was better than placebo in improving pain in OA patients. The benefit was estimated to be small to moderate, but clinically meaningful. Such efficacy, together with the low risk of their use, supports why these products are popular among OA sufferers. ${ }^{18}$

Despite some negative data and controversy around, ${ }^{19,20}$ moderate to high quality evidence supports that GS/CS produce pain reduction and physical function improvement in OA patients with good safety. ${ }^{14} \mathrm{GS} / \mathrm{CS}$ treatment given for 6 months has demonstrated comparable efficacy to celecoxib, a COX2 inhibitor, for reducing pain, stiffness, functional limitation and joint swelling in patients with painful knee OA. ${ }^{21}$ Hence, GS/CS is a good comparator for new substances of natural origin that pretend help in OA management.

D-002, a mixture of six high molecular weight aliphatic alcohols purified from beeswax, ${ }^{22}$ has demonstrated to inhibit both cycloxygenase (COX) and 5-lipooxygenase (5-LOX) activities in vitro. ${ }^{23}$ Oral administration of D-002 has been effective in experimental inflammation ${ }^{24,25}$ and in the model of monoiodoacetate (MIA)-induced OA in rats, in which D-002 displayed chondroprotective effects, decreasing cartilage injury. ${ }^{26}$ Also, D-002 $(50 \mathrm{mg} /$ day) given for 6-8 weeks reduced significantly $O A$ symptoms and the need of using rescue medica- tions in OA subjects, ${ }^{27,}{ }^{28}$ being suggested the potential usefulness of D-002 for managing OA. ${ }^{29}$ In light of these issues, this study compared the effects of D-002 and GS/SC, administered for 12 weeks, on OA symptoms.

\section{Methods \\ Study design}

This randomized, open, comparator (GS/CS) controlled study was approved by the Institutional Ethics Committee of the Surgical Research Centre (Havana, Cuba) and registered on the Cuban Public Registry of Clinical Trials (RPCEC00000180) The study was conducted according to the ethical standards of the Declaration of Helsinki. At enrolment, subjects provided their informed written consent after received, in a plain and understabler language, oral and written explanations about the purpose and details of the trial.

Eligible patients were randomized, to GS/CS (375/300 mg) or $50 \mathrm{mg} \mathrm{D-002} \mathrm{once} \mathrm{daily} \mathrm{for} 12$ weeks. Randomized subjects attended to visits every two weeks. Physical examinations, treatment compliance, symptom assessment, use of rescue medications and $A E$ were controlled at each visit post-randomization. Laboratory examinations were done at baseline and after 6 and 12 weeks on treatment.

\section{Study participants}

The study enrolled ambulatory women and men (20 - 80 years) previously diagnosed of suffering knee, hip or finger OA, supported by clinical and radiological criteria. Participants should have a diagnosis of functional class I, II or III (mild to moderate) according to the American College of Rheumatology Criteria (ACRC) ${ }^{30,31}$ and a Western Ontario and McMaster Individual Osteoarthritis Index (WOMAC) $\geq 25 .{ }^{32}$

Exclusion criteria were other forms of arthritis, arthroscopy performed within the past year, intra-articular injection of steroids within the past 3 months, uncontrolled hypertension (diastolic pressure 120 $\mathrm{Hg} \mathrm{mm}$ ) or diabetes (fasting glucose $>7 \mathrm{mmol} / \mathrm{L}$ ), active liver or renal disease, malignancies, any other serious illnesses, hospitalization during the 6 months prior to the study or the following laboratory abnormalities: alanine -ALT- and/or aspartate -AST-amino transferase $>45 \mathrm{U} / \mathrm{L}$, creatinine $>130$ 
$\mu \mathrm{mol} / \mathrm{L}$. Pregnant women, nursing women, and those not taking adequate contraceptive measures were also excluded.

Predefined premature discontinuations included unwillingness to follow-up, any $A E$ supporting such decision and protocol violations (failure of tablets intake $\geq 5$ days).

\section{Treatment}

Tablets of D-002 (50 mg) (Laboratorios MedSol, Havana, Cuba) and GS/SC (375/300 mg) (Aspen Pharma Pty Ltd, NSW, Australia) were used in the trial. The content of D-002 in the tablets was assessed by gas chromatography. ${ }^{33}$ Treatments were packaged in plastic bottles.

Eligible patients were randomly allocated to receive D-002 or GS/SC tablets. The tablets should be taken one per day with the breakfast for 12 weeks. The randomisation code was computer-generated with a fixed, not stratified randomisation method, using balanced blocks of 8 and allocation ratio of $1: 1$. The doses of D-002 have been used in previous clinical studies in OA patients. ${ }^{27,28}$

Treatment compliance was controlled by counting the remainder tablets and interviewing the subjects. At study completion, non-used tablets were recovered. Compliance was considered good if the partitipants have taken at least $85 \%$ of the tablets scheduled from the previous visit.

Consumption of NSAIDs, steroids, cartilage or calcium supplements, or any other agent that may affect the study outcomes was forbidden, except that of rescue medications needed to treat persistent pain: acetaminophen (maximum $2 \mathrm{~g} /$ day) or metamizole (maximum $600 \mathrm{mg} /$ day). Participants filled a daily record of their consumption of rescue medications, which was reported at each next scheduled visit, when the number of consumed rescue medication was recorded.

\section{Study outcomes}

The primary study outcome was a significant reduction of the total WOMAC index $\geq 30 \%$ as compared to baseline. The WOMAC questionnaire consists of three sections, one that assess pain intensity (5 questions), other joint stiffness (2 questions), and the third the physical function (17 questions). Individual responses were sco- red on the following scale: 0 (none), 1 (slight), 2 (moderate), 3 (severe) and 4 (extreme). The total score ranges from 0 (the best) to 96 (the worst). This tool provides a validated assessment of the patient's functional capacity, specifically joint pain, stiffness and functional impairment, being useful for the evaluation of the effect of investigation products on OA symptoms. ${ }^{32,34-36}$

Significant decreases in pain, stiffness and physical function WOMAC scores, ${ }^{32,34-36}$ as well as in the Visual Analogy Scale (VAS) score (specific for pain) ${ }^{37,38}$ were secondary outcomes. In order to avoid biases, subjects answered to both WOMAC and VAS questionnaires in the doctor's office before their examination. The VAS-visual analogy scale score used a $100 \mathrm{~mm}$ linear measure of pain status with 0 representing no pain and 100 the worst suffered pain. Participants marked on the linear scale the relevant amount of pain they were suffering, and the value was noted.

Rescue medications use was another secondary outcome. The amount of rescue medication was assessed in terms of total use at study completion. All primary and secondary outcome measures were assessed at each visit.

The subjective self-perception of symptom relief at trial completion was a collateral outcome. This matter was assessed according to 4 options: very good (complete symptoms relief), good (remarkable symptom relief, but some symptoms still remaining), fairly (modest symptom relief) and poor (no symptom relief or worsening of symptoms).

\section{Safety and tolerability assessment}

Safety variables included physical (body weight, pulse rate, blood pressure) and blood indicators (alanine aminotransferase -ALT-, aspartate aminotransferase-AST-, serum fasting glucose, creatinine, cholesterol, triglycerides). Blood biochemistry indicators were assessed by using reagent kits (Roche, Switzerland) and performed in the Hitachi 709 autoanalyser (Tokyo, Japan).

Analyses were done at the clinical laboratory of the Surgical and Medical Research Centre (Havana, Cuba). Controls of the precision and accuracy of the methods were performed.

An AE was any undesirable event that newly appeared to a subject during the study, disregarding 
the cause. At each visit subjects were queried about $A E$, which were recorded in case record forms, including their characteristics, dates of onset and disappearance, treatments adopted and responses achieved.

According to their severity, AE were classified as mild, moderate or serious. Mild AE were those easily tolerated so that did not not require suspension of study treatments and/or specific intervention, moderate those that caused discomfort enough for requiring stopping therapy and/or specific intervention, and serious those disabling events leading to hospitalisation and/or deaths. AEs that occurred within 30 days of consuming the last dose, monitored by direct contact with the subjects, were included in the analysis. The causal relationships between $\mathrm{AEs}$ and the treatments were classified by using the Naranjo algorithm. ${ }^{39}$

\section{Statistical Analysis}

Data were analysed as per the intention to treat approach. So, data of all randomized subjects were included in all analyses. The sample size estimation assumed a difference of $20 \%$ between the reductions of WOMAC total scores from baseline with each treatment at study completion. Then, 30 subjects per arm (60 participants) would be sufficient to detect such difference with $80 \%$ power and $\alpha=0.05$. Assuming a permissible dropout rate of $10 \%, 66$ subjects were enrolled.

With the exception of the final value of the study withdrawal, there were not others missing data in the WOMAC and VAS scores. Continuous data were compared by using the Wilcoxon test for matched samples (comparisons within groups) and the Mann Whitney $U$ test (between group comparisons). Bonferroni adjustment for multiple comparisons was applied. ${ }^{40}$ Categorical variables were compared with the Fisher Exact Probability test. All statistical tests for differences were 2-tailed. $p<0.05$ was considered for statistical significance. Comparisons were done by using the Statistics software for Windows (USA) and MS Excel. Statistical significance was taken at the $95 \%$ level $(p<0.05)$.

\section{Results \\ Baseline characteristics}

Sixty-six (66) subjects were recruited for the study. Of them, 60 were eligible for randomization. Six subjects were not eligible because of having fasting glucose $>7 \mathrm{mmol} / \mathrm{L}$ (4 subjects) and a diagnosis of rheumatoid arthritis (2).

Baseline characteristics were well balanced in the two groups, so that treatment allocation was well randomized effective (Table 1 ).

Most study patients were women $(53,88.3 \%)$, $49 / 53$ postmenopausicas ( $92.5 \%$ ). Thirty one subjects $(29,48.3 \%)$ were above the normal weight (25 just overweight, 4 obeses). The frequency of hypertension (35/60, $58.3 \%)$, and hypercholesterolemia $(31 / 60,51.7 \%)$ was also high $(>50 \%)$, and the same was true for sedentary life $(53 / 60$, $88.3 \%)$, a negative lifestyle factor. Smokers $(3 / 60$, $5 \%$ ), however, accounted for only $5 \%$ of study population. Consumption of concomitant therapy $(59 / 60)$ was very high $(98.3 \%)$.

Of 60 randomized patients, $59(98.3 \%)$ completed the trial. One patient (D-002) withdrew from the study due to an $A E$ (skin rash).

Adherence to study protocol was excellent, and treatment compliance was very good $(\geq 90 \%)$ and similar in both study groups.

\section{Efficacy analysis}

Table 2 summarizes the effects on total WOMAC scores (mean $\pm \mathrm{SD}$ ).

The mean baseline total WOMAC scores were similar in two groups: 35.9 (D-002) and 36.8 (GS/ SC). After 2 weeks on treatment D-002 and GS/ CS reduced significantly $(p<0.00001)$ the total WOMAC score by $44.6 \%$ and $40.2 \%$ as compared to baseline. Thereafter, the decreases of the total score were not only persistent, but increased, so that significant $(p<0.00001)$ and marked reductions of $72.1 \%$ (D-002) and $78.5 \%$ (GS/SC) were seen at week 12. No significant differences between groups were found.

Both treatments decreased significantly pain (78.6\% with D-002, $84.3 \%$ with GS/SC), stiffness $(82.6 \%$ and $89.3 \%$, respectively) and function (67.9\% and $74.2 \%$, respectively) WOMAC scores from the second week on therapy. The treatment effects did not wear off, but were enhanced during the trial.

The mean baseline WOMAC pain scores were 
Table 1. Baseline characteristics of study population

\begin{tabular}{|c|c|c|c|c|c|c|}
\hline & \multicolumn{2}{|c|}{$D-002(n=30)$} & \multicolumn{2}{|c|}{ GS/SC $(n=30)$} & \multicolumn{2}{|c|}{ Total $(n=60)$} \\
\hline Age (years) (X SD) & \multicolumn{2}{|c|}{$68 \pm 7$} & \multicolumn{2}{|c|}{$67 \pm 9$} & \multicolumn{2}{|c|}{$68 \pm 8$} \\
\hline Body mass index $\left(\mathrm{kg} / \mathrm{m}^{2}\right)(X \pm S D)$ & \multicolumn{2}{|c|}{$25.2 \pm 4.0$} & \multicolumn{2}{|c|}{$23.7 \pm 4.0$} & \multicolumn{2}{|c|}{$24.4 \pm 4.0$} \\
\hline \multicolumn{7}{|l|}{ Total WOMAC scores $(\mathrm{X} \pm \mathrm{SD})$} \\
\hline & $\mathrm{n}$ & $\%$ & $\mathrm{n}$ & $\%$ & $\mathrm{n}$ & $\%$ \\
\hline Women & 28 & 93.3 & 25 & 83.3 & 53 & 88.3 \\
\hline Men & 2 & 6.7 & 5 & 16.7 & 7 & 11.7 \\
\hline \multicolumn{7}{|l|}{ Degree of OA according to ACRC } \\
\hline 1 & 0 & 0.0 & 3 & 10.0 & 3 & 5.0 \\
\hline ॥ & 23 & 76.7 & 20 & 66.7 & 43 & 71.7 \\
\hline III & 7 & 23.3 & 7 & 23.3 & 14 & 23.3 \\
\hline \multicolumn{7}{|l|}{ OA diagnosis } \\
\hline Knee & 28 & 93.3 & 29 & 96.7 & 57 & 95.0 \\
\hline Hip & 20 & 66.7 & 22 & 73.3 & 42 & 70.0 \\
\hline Hand/fingers & 21 & 70.0 & 25 & 83.3 & 46 & 76.7 \\
\hline Mixed & 30 & 100.0 & 29 & 96.7 & 59 & 98.3 \\
\hline \multicolumn{7}{|l|}{ Main concomitant conditions } \\
\hline Hypertension & 18 & 60.0 & 17 & 56.7 & 35 & 58.3 \\
\hline Hypercholesterolemia & 13 & 43.3 & 18 & 60.0 & 31 & 51.7 \\
\hline Overweight $(\mathrm{kg} / \mathrm{m} 2 \geq 25,<30)$ & 15 & 50.0 & 10 & 33.3 & 25 & 41.7 \\
\hline Diabetes mellitus & 5 & 16.7 & 6 & 20.0 & 11 & 18.3 \\
\hline Thyroid dysfunction & 4 & 13.3 & 3 & 10.0 & 7 & 11.7 \\
\hline Coronary heart disease (CHD) & 3 & 10.0 & 1 & 3.3 & 4 & 6.7 \\
\hline Obesity $\left(\mathrm{kg} / \mathrm{m}^{2} \geq 30\right)$ & 2 & 6.7 & 2 & 6.7 & 4 & 6.7 \\
\hline \multicolumn{7}{|l|}{ Lifestyle factors } \\
\hline Sedentary life & 29 & 96.7 & 24 & 80.0 & 53 & 88.3 \\
\hline Smoking & 2 & 6.7 & 1 & 3.3 & 3 & 5.0 \\
\hline \multicolumn{7}{|l|}{ Concomitant therapy a } \\
\hline Consumers of at least one concomitant drug & 29 & 96.7 & 30 & 100.0 & 59 & 98.3 \\
\hline Diuretics & 9 & 30.0 & 11 & 36.7 & 20 & 33.3 \\
\hline Cholesterol-lowering drugs & 8 & 26.7 & 12 & 40.0 & 20 & 33.3 \\
\hline Angiotensin converting enzyme inhibitors & 7 & 23.3 & 8 & 26.7 & 15 & 25.0 \\
\hline$\beta$-blockers & 7 & 23.3 & 2 & 6.7 & 9 & 15.0 \\
\hline Antiplatelet drugs & 5 & 16.7 & 4 & 13.3 & 9 & 15.0 \\
\hline Oral hypoglycemic drugs & 3 & 10.0 & 2 & 6.7 & 5 & 8.3 \\
\hline Calcium antagonists & 2 & 6.7 & 3 & 10.0 & 5 & 8.3 \\
\hline Anxyolitics & 2 & 6.7 & 3 & 10.0 & 5 & 8.3 \\
\hline
\end{tabular}

SD standard deviation, OA osteoarthritis, ACRC American College of Rheumatology Criteria;

a The table includes only those consumed by $\geq 5$ subjects; No significant between group differences were found.

(Mann Whitney U test, Fisher Exact Probability test for categorical variables) 
Table 2. Changes in the total Western Ontario and McMaster Individual Osteoarthritis Index (WOMAC) scores

\begin{tabular}{llc} 
Week & \multicolumn{2}{l}{ WOMAC Index scoresa } \\
& $\mathrm{D}-002$ & GS/SC \\
0 (baseline) & $35.9 \pm 5.1$ & $36.8 \pm 5.7$ \\
2 & $19.9 \pm 4.7 \mathrm{~b}$ & $22.0 \pm 8.0 \mathrm{~b}$ \\
4 & $14.0 \pm 7.8 \mathrm{~b}$ & $12.8 \pm 8.2 \mathrm{~b}$ \\
6 & $14.4 \pm 7.7 \mathrm{~b}$ & $12.2 \pm 8.1 \mathrm{~b}$ \\
8 & $11.9 \pm 7.3 \mathrm{~b}$ & $10.3 \pm 7.6 \mathrm{~b}$ \\
10 & $12.3 \pm 7.5 \mathrm{~b}$ & $9.9 \pm 10.4 \mathrm{~b}$ \\
12 & $10.0 \pm 6.9 \mathrm{~b}$ & $7.9 \pm 7.6 \mathrm{~b}$ \\
$\%$ change & -72.1 & -78.5
\end{tabular}

Values are means $\pm S D, G S / C S$ glucosamine/chondroitin sulfate a Divided into three domains: pain, stiffness and physical function. Each domain has several items and each one is graded in a scale of 0 (none) to 4 (extreme), the lowest being the better, the highest the worst. There were a total of 24 items in the total WOMAC score b $p<0.00001$ Comparisons versus baseline (Wilcoxon test for matched samples, Bonferroni adjustment)

11.2 (D-002) and 11.5 (GS/SC). At week 2 (first interim check-up), pain score had lowered significantly reduced with D-002 and GS/SC $(p<0.00001$ versus baseline for both comparisons). The effect was enhanced over the trial. At the end of the study the WOMAC pain scores lowered significantly to 2.4 (D-002) and 1.8 (GS/SC). In turn, the mean stiffness WOMAC scores decreased significantly $(p<0.00001$ versus baseline) from 2.3 to 0.4 (D002 ), and from 2.8 to 0.3 (GS/SC), and physical function WOMAC scores lowered $(p<0.00001$ versus baseline) from 22.4 to 7.2 (D-002) and from 22.5 to 5.8 (GS/SC) (Table 3).

Table 4 lists the effects on the mean VAS score. After 2 weeks on treatment D-002 and GS/SC reduced significantly $(p<0.0001)$ the VAS score versus baseline. The effects on VAS score, progressively enhanced thereafter, achieved percent decreases versus baseline of $76.6 \%$ (D-002) and $76.8 \%$ (GS/SC) at the end of the study.

The frequency of patients who required rescue medications (acetaminophen or metamizole) in each group) (3 D-002, 4 GS/SC) was indistinguishable.

The assessment of the self perceived efficacy of treatments found that $12 / 30(40 \%)$ and $9 / 30$ $(30 \%)$ of D-002 patients, respectively, classified the efficacy as very good and good, respectively, so that $21 / 30(70 \%)$ was happy with the efficacy. In turn, $10 / 30(33.3 \%)$ and $15 / 30(50 \%)$ of the patients treated with GS/CS reported a very good and good efficacy, respectively, for a total of 25/30 $(83.3 \%)$ cases who found that efficacy was satisfactory. Results in both groups were statistically comparable.

Table 3. Changes in pain, stiffness and physical function WOMAC scores

$\begin{array}{lccrrrrr}\text { Treatment } & \text { Baseline } & \text { 2 weeks } & \text { 4 weeks } & \mathbf{6} \text { weeks } & \mathbf{8} \text { weeks } & \mathbf{1 0} \text { weeks } & \mathbf{1 2} \text { weeks } \\ \text { Pain score } \mathrm{a} & & & & & & \\ \text { D-002 } & 11.2 \pm 2.2 & 5.8 \pm 2.3 \mathrm{~b} & 4.3 \pm 2.6 \mathrm{~b} & 4.0 \pm 2.5 \mathrm{~b} & 3.2 \pm 2.3 \mathrm{~b} & 3.0 \pm 2.1 \mathrm{~b} & 2.4 \pm 2.2 \mathrm{~b} \\ \text { GS/SC } & 11.5 \pm 2.3 & 6.3 \pm 2.9 \mathrm{~b} & 4.0 \pm 2.5 \mathrm{~b} & 3.8 \pm 2.8 \mathrm{~b} & 2.9 \pm 2.8 \mathrm{~b} & 2.6 \pm 2.4 \mathrm{~b} & 1.8 \pm 1.9 \mathrm{~b} \\ \text { Stiffness score a } & & & & & & \\ \text { D-002 } & 2.3 \pm 1.3 & 0.7 \pm 0.7 \mathrm{~b} & 0.5 \pm 0.7 \mathrm{~b} & 0.4 \pm 0.6 \mathrm{~b} & 0.4 \pm 0.9 \mathrm{~b} & 0.3 \pm 0.7 \mathrm{~b} & 0.4 \pm 0.7 \mathrm{~b} \\ \text { GS/SC } & 2.8 \pm 1.5 & 1.4 \pm 1.4 \mathrm{~b} & 0.6 \pm 0.7 \mathrm{~b} & 0.4 \pm 0.5 \mathrm{~b} & 0.2 \pm 0.4 \mathrm{~b} & 0.5 \pm 1.0 \mathrm{~b} & 0.3 \pm 0.6 \mathrm{~b} \\ \text { Physical function } \mathrm{a} & & & & & & \\ \text { D-002 } & 22.4 \pm 3.8 & 13.3 \pm 3.2 \mathrm{~b} & 9.2 \pm 6.1 \mathrm{~b} & 10.0 \pm 5.9 \mathrm{~b} & 8.3 \pm 5.6 \mathrm{~b} & 9.0 \pm 5.7 \mathrm{~b} & 7.2 \pm 4.9 \mathrm{~b} \\ \text { GS/SC } & 22.5 \pm 3.6 & 14.3 \pm 5.2 \mathrm{~b} & 8.3 \pm 6.4 \mathrm{~b} & 7.9 \pm 6.0 \mathrm{~b} & 7.2 \pm 5.7 \mathrm{~b} & 6.7 \pm 7.7 \mathrm{~b} & 5.8 \pm 6.0 \mathrm{~b}\end{array}$

Values are means \pm Standard Deviation, GS/CS glucosamine/chondroitin sulfate

a Measured on the following scale $(0-4$, where $0=$ none, $1=$ slight, $2=$ moderate, $3=$ severe, $4=$ extreme $)$. The lowest the better, the highest the worst

b $p<0.00001$ Comparisons versus baseline (Wilcoxon test for matched samples, Bonferroni adjustment) 
Table 4. Changes in VAS scores ${ }^{a}$

\begin{tabular}{llllllll} 
Treatment & Baseline & $\mathbf{2}$ weeks & $\mathbf{4}$ weeks & $\mathbf{6}$ weeks & $\mathbf{8}$ weeks & \multicolumn{1}{c}{$\mathbf{1 0}$ weeks } & $\mathbf{1 2}$ weeks \\
D-002 & $64.0 \pm 22.4$ & $49.2 \pm 21.0 \mathrm{~b}$ & $42.3 \pm 21.6 \mathrm{~b}$ & $39.5 \pm 23.1 \mathrm{C}$ & $30.0 \pm 20.4 \mathrm{C}$ & $24.8 \pm 18.2 \mathrm{C}$ & $15.0 \pm 16.3 \mathrm{C}$ \\
$\mathbf{G S / S C}$ & $71.0 \pm 23.7$ & $58.2 \pm 21.7 \mathrm{C}$ & $41.5 \pm 22.4 \mathrm{C}$ & $38.3 \pm 26.3 \mathrm{C}$ & $32.5 \pm 25.2 \mathrm{C}$ & $28.5 \pm$ & $16.5 \pm 15.2 \mathrm{C}$
\end{tabular}

Values are means \pm Standard Deviation, GS/CS glucosamine/chondroitin sulfate

a Measured on a $100 \mathrm{~mm}$ scale of 0 to 100 , where $0=$ no pain and 100 was the worst possible pain

b $p<0.0001 ; c p<0.00001$ Comparisons versus baseline (Wilcoxon test for matched samples, Bonferroni adjustment)

\section{Safety and tolerability}

Treatments were well safe and tolerated. Vital signs and blood parameters were not affected by the treatments, and individual values remained within normal ranges (data not shown for simplicity).

There was only one study withdrawal (D-002), which was motivated by a moderate $A E$ (skin rash) treated with topical corticoids. Other three subjects (1 in D-002 group, 2 in GS/SC group) referred some $A E$ during the trial: urinary infection (D-002), heartburn (GS/SC) and stomach pain (GS/SC). No significant differences between the groups were noted.

\section{Discussion}

The progression of $\mathrm{OA}$ affects the quality of life of the sufferers. ${ }^{1-3}$ Pain decrease and improved function are the main objectives in OA management, which mainly involves medical treatment and lifestyle modifications. The consumption of NSAIDs for pain management in OA is highly frequent, but they increase the risk of gastrointestinal bleeding and cardiovascular adverse events. 4-6 Second-line treatments (SYSADOA), not included in all guidelines, improve OA symptoms, reduce cartilage degradation, and have a better gastrointestinal profile as compared to NSAIDs, but the onset of their effects is more delayed. ${ }^{12,13}$

This study demonstrates that administration of D-002 (50 mg/day) and GS/SC (375/300 mg) for 12 weeks produce a significant improvement in the total WOMAC score, main study outcome, in patients with mild to moderate OA. Similar effects were seen on pain, stiffness, and physical function
WOMAC scores, and on the VAS score for pain. The score decreases were significant from the first interim-ckeck up conducted after concluding 2 weeks on therapy, and were enhanced throughout the study. The efficacy of both treatments was remarkable and comparable.

Since the two study groups were homogeneous at baseline, the randomized allocation of treatments should be accepted as adequate and the results here seen as attributable to the treatment, not to initial differences between them. The mean age of study population (68 years) is consistent with the fact that $O A$ is a disease predominant in older people. ${ }^{1-3}$ The frequency of women $(88.3 \%)$, higher than that of men $(11.7 \%)$, agrees with the high frequency of OA reported in older women. ${ }^{41}$ The high frequency of co-morbidities (overweight plus obesity, hypertension and hypercholesterolemia), and of lifestyle risk factors (sedentary life) between study subjects reflects the coexistence of concomitant coronary risk factors in middle-aged and older subjects with OA. ${ }^{42,43}$

Both treatments produced significant reductions of the total (main study outcome) and pain, stiffness and functional activity WOMAC scores (secondary outcomes), evident from the second week and enhanced thereafter. At study completion D-002 and GS/CS had decreased the total WOMAC score ( $72.1 \%$ and $78.5 \%$ versus baseline, respectively). In turn, the reduction of VAS score was also significant from the second week on treatment and increased progressively over the study, with final decreases of $76.6 \%$ (D-002) and $76.8 \%$ (GS/SC) versus baseline. The reductions of the WOMAC 
pain and the VAS scores were grossly comparable. The decreases of all the scores were marked and comparable in the two groups.

The decrease in pain was both clinically important and statistically significant $(78.6 \%$ reduction with D-002 vs $84.3 \%$ with GS/SC), as was the improvement in stiffness $(82.6 \%$ with $\mathrm{D}-002$ vs $89.3 \%$ with GS/SC), and function $(67.9 \%$ vs $74.2 \%$, respectively). Similar reductions were seen in VAS $(76.6 \%$ vs $76.8 \%$, respectively), without differences between treatments.

The efficacy of GS/CS on WOMAC scores here reported, however, is higher than that referred by other authors. ${ }^{21}$ A double-blind, randomized study found that GS $(500 \mathrm{mg}) / \mathrm{CS}(450 \mathrm{mg})$ given three times a day for 6 months decreased significantly WOMAC pain $(50.1 \%)$, stiffness $(46.9 \%)$ and function scores (45.5\%), similar to celecoxib $200 \mathrm{mg} /$ day given once a day $(50.2 \%, 49.2 \%$ and $46.4 \%$ reductions for WOMAC pain, stiffness and function scores, respectively; and $48.8 \%$ for VAS score). ${ }^{21}$

Since we used lower dose and shorter administration, the effect here seen (all reductions higher than $70 \%$ ) are appreciably better, perhaps because our study was conducted in patients with mild to moderate symptoms, esier to control. In such regard, the efficacy of D-002 is consistent with that referred previously in subjects with mild to moderate OA. ${ }^{27,} 28$ This study, however, had a duration (12 weeks) longer than that of previous studies of D-002 on OA (6 -8 weeks) basically because the comparator (GS/SC), albeit provided longlasting pain relief and functional improvement in OA, has a slow onset of response as compared to NSAIDS. ${ }^{12,13,44}$

The mechanisms whereby D-002 and GS/SC may alleviate OA symptom are beyond the objective of this study. Nevertheless, GS and SC produce antiinflammatory and chondroprotective effects involving the inhibition of metalloproteinase activity, prostaglandin E2 release, nitric oxide production and glycosaminoglycans degradation, and the increase of hyaluronic acid synthesis in the joint. CS stimulates collagen synthesis, whereas GS inhibits prostaglandin release, both substances together exhibiting synergic benefits. ${ }^{17,45,46}$

In contrast, D-002 inhibits COX and 5-LOX activities ${ }^{23}$ and produces a chondroprotective effect demonstrated experimentally. ${ }^{26}$

Interestingly, differently from the gastrotoxicity induced by NSAIDs, ${ }^{10,13}$ D-002 produces gastroprotection. ${ }^{47-49}$ The gastroprotective effect of D-002 involves the increased the secretion and improved composition of the gastric mucus, ${ }^{47}$ a defensive factor of the gastric mucosa, and the reduction of hydroxyl radical generation, lipid peroxidation and protein oxidation in the gastric mucosa. 48,49

Administration of D-002 and GS/SC exhibited a good safety and tolerability, coherently with previous data on both treatments.

This trial has some limitations. First, the assiginement of treatments was open, not blind, which cannot exclude the presence of subjective biases from patients and doctors, a matter of more relevance when the nature of the response is subjective, as the answer to any questionnaire, even validated. Second, the use of a placebo group was not considered adequate because the efficacy of GS/SC (the comparator) was considered as well established and the treatment of widespread use. Additionally, both treatment groups have already demonstrated superiority versus placebo in randomised controlled trials. ${ }^{27,} 28,50$

The results of present study are extrapolable to patients with mild to moderate OA. Our data support that the efficacy and safety of D-002 is comparable to that of GS/SC in the management of these patients, and suggest that D-002 could be another alternative, mainly for patients who have contraindications for treatment with NSAIDs or paracetamol.

\section{Conclusion}

The present results, in addition to confirm the efficacy of D-002 and GS/SC in ameliorating OA symptoms, demonstrate, for the first time, that the efficacy and tolerability of the two treatments are comparable.

\section{References}

1. Murray CJ, Vos T, Lozano R, Naghavi M, Flaxman AD, Michaud C, et al. Disability-adjusted life years (DALYs) for 291 diseases and injuries in 21 regions, 1990-2010: a systematic analysis for the Global Burden of Disease Study 2010. Lancet 2012; 380:2197- 
223.

2. London: National Institute for Health and Care Excellence; 2014. National Institute for Health and Care Excellence. Osteoarthritis care and management in adults. Clinical Guide 177.

3. Marshall DA, Vanderby S, Barnabe C, MacDonald KV, Maxwell C, Mosher D, Wasylak T, Lix L, Stat $P$, Enns E, Frank C, Noseworthy T. Estimating the Burden of Osteoarthritis to Plan for the Future. Arthritis Care Res (Hoboken). 2015, May 4. doi: 10.1002/acr.22612. [Epub ahead of print]

4. Edwards JJ, Khanna M, Jordan KP, Jordan JL, Bedson J, Dziedzic KS. Quality indicators for the primary care of osteoarthritis: A systematic review. Ann Rheum Dis 2013; 0:1-9.

5. Allen KD, Bierma-Zeinstra SM, Foster NE, Golightly YM, Hawker G. Osteoarthritis Cartilage 2015; 23(5):826-838.

6. Zhang W, Moskowitz RW, Nuki G, Abramson $S$, Altman RD, Arden N, Bierma-Zeinstra S, Brandt $K D$, Croft $P$, Doherty $M$, Dougados $M$, Hochberg $M$, Hunter DJ, Kwoh K, Lohmander LS, Tugwell P. OAR$S I$ Recommendations for the management of hip and knee osteoarthritis. Part l: critical appraisal of existing treatment guidelines and systematic review of current research evidence. Osteoarthritis Cartilage 2007; 15 (9): 981-1000.

7. Zhang W, Moskowitz RW, Nuki G, Abramson $S$, Altman RD, Arden N, Bierma-Zeinstra S, Brandt KD, Croft $P$, Doherty M, Dougados M, Hochberg M, Hunter DJ, Kwoh K, Lohmander LS, Tugwell P. OARSI recommendations for the management of hip and knee osteoarthritis, Part II: OARSI evidence-based, expert consensus guidelines. Osteoarth Cartilage 2008;16 (2):137-62.

8. Lee YC, Shmerling RH. The benefit of nonpharmacologic therapy to treat symptomatic osteoarthritis. Curr Rheumatol Rep 2008; 10: 5-10.

9. Hochberg MC, Altman RD, April KT, Benkhalti M, Guyatt G, McGowan J, Towheed T, Welch V, Wells G, Tugwell P. American College of Rheumatology 2012 recommendations for the use of nonpharmacologic and pharmacologic therapies in osteoarthritis of the hand, hip, and knee. Arthritis Care Res 2012; 64 (4):465-74.

10. McCarberg B, Tenzer P. The complexities in the pharmacologic management of osteoarthritis pain. Curr Med Res Opin 2013; 29: 539-548.

11. Bruyère O, Cooper C, Pelletier JP, Branco J, Luisa Brandi M, Guillemin F, Hochberg MC, Kanis JA, Kvien TK, Martel-Pelletier J, Rizzoli R, Silverman S, Reginster JY. An algorithm recommendation for the management of knee osteoarthritis in Europe and internationally: a report from a task force of the European
Society for Clinical and Economic Aspects of Osteoporosis and Osteoarthritis (ESCEO). Semin Arthritis Rheum 2014; 44(3):253-63.

12. Cutolo M, Berenbaum F, Hochberg M, Punzi L, Reginster JY. Commentary on recent therapeutic guidelines for osteoarthritis. Semin Arthritis Rheum 2015 Jun; 44(6):611-7.

13. Yeomans ND. Consensus about managing gastrointestinal and cardiovascular risks of nonsteroidal anti-inflammatory drugs. BMC Med 2015 Mar 19; 13:56.

14. Bruyere O, Burlet N, Delmas PD, Rizzoli $R$, Cooper C, Reginster JY. Evaluation of symptomatic slow-acting drugs in osteoarthritis using the GRADE system. BMC Musculoskelet Disord. 2008 Dec 16;9:165. doi: 10.1186/1471-2474-9-165.

15. Hochberg MC, Zhan M, Langenberg $P$. The rate of decline of joint space width in patients with osteoarthritis of the knee: a systematic review and meta-analysis of randomized placebo-controlled trials of chondroitin sulfate. Curr Med Res Opin 2008; 24:3029-35.

16. Lee YH, Woo JH, Choi SJ, Ji JD, Song GG. Effect of glucosamine or chondroitin sulfate on the osteoarthritis progression: a meta-analysis. Rheumatol Int 2010; 30:357-63.

17. Henrotin Y, Lambert C. Chondroitin and glucosamine in the management of osteoarthritis: an update. Curr Rheumatol Rep 2013; 15:361.

18. Singh JA, Noorbaloochi S, MacDonald $R$, Maxwell LJ. Chondroitin for osteoarthritis. Cochrane Database Syst Rev 2015; 1:CD005614.

19. Wandel S, Juni P, Tendal B, Nuesch E, Villinger PM, Welton NJ, et al. Effects of glucosamine, chondroitin, or placebo in patients with osteoarthritis of hip or knee: network meta-analysis. BMJ 2010; 341:c4675. 20. Yang S, Eaton CB, McAlindon TE, Lapane KL. Effects of glucosamine and chondroitin supplementation on knee osteoarthritis: an analysis with marginal structural models. Arthritis Rheumatol. 2015; 67:71423.

21. Hochberg MC, Martel-Pelletier J, Monfort J, Möller I, Castillo JR, Arden N, Berenbaum F, Blanco FJ, Conaghan PG, Doménech G, Henrotin Y, Pap T, Richette P, Sawitzke A, du Souich P, Pelletier JP on behalf of the MOVES Investigation Group. Combined chondroitin sulfate and glucosamine for painful knee osteoarthritis: a multicentre, randomised, double-blind, non-inferiority trial versus celecoxib. Ann Rheum Dis. 2015 Jan 14. pii: annrheumdis-2014-206792. doi: 10.1136/annrheumdis-2014-206792. [Epub ahead of print]

22. Mas R. D-002: A product obtained from beeswax. Drugs of the Future. 2001; 26: 731-744. 
23. Pérez Y, Oyarzábal A, Ravelo Y, Mas R, Jiménez S, Molina V. Inhibition of COX and 5-LOX enzymes by D-002 (beeswax alcohols). Curr Top Nutraceutical Res 2014; 12(1/2): 13-18.

24. Carbajal D, Molina V, Valdés S, Arruzazabala $M L$, Mas R, Magraner J. Anti-inflammatory activity of D-002: an active product isolated from beeswax. Prostagl. Leukotr. Essent. Fatty Acids 1998; 59: 235-238.

25. Ravelo Y, Molina V, Carbajal D, Fernández $L$, Fernández J, Arruzazabala ML, mas $R$, Hernández $C$. Evaluation of anti-inflammatory and antinociceptive effects of Abexol (beeswax alcohols). J Nat Med 2010; 65: 330-335.

26. Mendoza S, Noa M, Valle M, Mendoza N, Mas $R$. Ameliorating effects of D-002, a mixture of beeswax alcohols, on monosodium iodoacetate-induced osteoarthritis in rats. IJPSRR 2013; 19: 10-15.

27. Rodríguez I, Mendoza S, IIInait J, Mas R, Fernández JC, Fernández $L$, Mesa M, Gámez R. Effects of $D-002$, a mixture of beeswax alcohols, on osteoarthritis symptoms: a randomized placebo-controlled study. IOSRPHR 2012; 2 (6): 1-9.

28. Puente $R$, Illnait J, Mas R, Carbajal D, Mendoza $S$, Fernández JC, Mesa $M$, Gámez $R$, Reyes $P$. Evaluation of the effect of D-002, a mixture of beeswax alcohols, on osteoarthritis symptoms. Korean J Intern Med. 2014;29(2):191-202.

29. Kim HS. Can natural products serve as potential treatments for osteoarthritis? Korean J Intern Med 2014; 29(2):173-5.

30. Altman R, Asch E, Bloch D, Bole G, Borenstein $D$, Brandt $K$, et al. The American College of Rheumatology Criteria for the classification and reporting of osteoarthritis of the knee. Arthritis Rheum 1986; 29 (8): 1039-1049.

31. Altman R, Alarcón G, Appelrouth D, Bloch D, Borenstein D, Brandt K, et al. The American College of Rheumatology Criteria for the classification and reporting of osteoarthritis of the hip. Arthritis Rheum 1991; 34 (5): 505-514.

32. Batlle-Gualda E, Esteve-Vives J, Piera MC, Hargreaves $R$, Cutis J. Adaptación transcultural al cuestionario WOMAC especifico para artrosis de rodiIla y cadera. Rev Esp Reumatol 1999; 26: 38-45.

33. González V, Marrero D, Sierra $R$, Velásquez $C$, Vicente R. Nuevo método por Cromatografía Gaseosa Capilar para el análisis del ingrediente activo D002. Rev CENIC Cien Quim 2008; 39: 123-124.

34. Angst T, Aeschlimann A, Stuki G. Smallest detectable and minimal clinically important differences of rehabilitation intervention with their implication for required simple sizes using WOMAC and SF-36 quality of life measurement instruments in patients with osteoarthritis of the lower extremities. Arthritis Rheum 2001; 45: 384-391.

35. Jinks C, Jordan K, Croft P. Measuring the population impact of knee pain and disability with the Western Ontario and McMaster Universities Osteoarthritis Index (WOMAC). Pain 2002; 100: 55-64.

36. Salaffi $F$, Leardini $G$, Canesi $B$, Mannoni $A$, Fioravanti A, Caporali R, Lapadula G, Punzi L. Reliability and validity of the Western Ontario and McMaster Universities (WOMAC) Osteoarthritis Index in Italian patients with osteoarthritis of the knee. Osteoarthritis Cartilage. 2003;11(8):551-60.

37. Gruenwald J, Petzold E, Busch R, Petzold HP, Graubaum HJ. Effect of glucosamine sulfate with or without omega-3 fatty acids in patients with osteoarthritis. Advances in Therapy 2009; 26: 858-871.

38. Goregaonkar A, Mathiazhagan $K J$, Shah $R R$, Kapoor PS, Taneja P, Sharma A, Bolmall C, Baliga VP. Comparative assessment of the effectiveness and tolerability of lornoxicam $8 \mathrm{mg}$ BID and diclofenac $50 \mathrm{mg}$ TID in adult Indian patients with osteoarthritis of the hip or knee: A 4-week, double-blind, randomized, comparative, multicenter study. Curr Ther Res 2009; 70 (1): 56-68.

39. Naranjo CA, Busto U, Sellers EM, Sandor $P$, Ruiz I, Roberts EA, Janecek E, Domecq C, Greenblatt DJ.. A method for estimating the probability of adverse drug reactions. Clin Pharmacol Ther 1981; 30 (2): 239245, 1981.

40. O'Brien P.C, Shampo M.C. Statistical considerations for performing multiple tests in a single experiment 5. Comparing two therapies with respect to several endpoints. Mayo Clin Proc 1988; 63: 1140-1143.

41. Srikanth VK, Fryer JL, Zhai G, Winzenberg TM, Hosmer D, Jones G. A meta-analysis of sex differences prevalence, incidence and severity of osteoarthritis. Osteoarthritis and Cartilage 2005; 13: 769-781. 42. Rizzoli $R$, Boonen $S$, Brandi ML, Bruyère $O$, Cooper C, Kanis JA, Kaufman JM, Ringe JD, Weryha $G$, Reginster JY. Vitamin D supplementation in elderly or postmenopausal women: a 2013 update of the 2008 recommendations from the European Society for Clinical and Economic Aspects of Osteoporosis and Osteoarthritis (ESCEO). Curr Med Res Opin 2013; 29(4): 305-313.

43. Singh G, Miller D, Lee FH, Pettitt D, Russell MW. Prevalence of cardiovascular disease risk factors among US adults with self-reported osteoarthritis: data from the Third National Health and Nutrition Examination Survey. Am J Manag Care 2002; 8: S383- S391.

44. Herrero-Beaumont G, Ivorra JA, Del Carmen Trabado M, Blanco FJ, Benito P, Martín-Mola E, Paulino J, Marenco JL, Porto A, Laffon A, Araújo D, Figueroa 
$M$, Branco J. Glucosamine sulfate in the treatment of knee osteoarthritis symptoms: a randomized, doubleblind, placebo-controlled study using acetaminophen as a side comparator. Arthritis Rheum 2007; 56:55567.

45. du Souich P. Absorption, distribution and mechanism of action of SYSADOAS. Pharmacol Ther 2014;142:362-74.

46. Lippiello L, Woodward J, Karpman R, Hammad TA. In vivo chondroprotection and metabolic synergy of glucosamine and chondroitin sulfate. Clin Orthop Relat Res 2000(381):229-40.

47. Carbajal D, Molina V, Noa M, Valdes S, Arruzazabala ML, Aguiar A, Más R. Effects of D-002 on gastric mucus composition in ethanol-induced ulcer. Pharmacol Res 2000; 42(4): 329-332.
48. Molina V, Valdés S, Carbajal D, Arruzazabala $L$, Menéndez R, Mas R. Antioxidant effects of $D$-002 on gastric mucosa of rats with experimentallyinduced injury. J Med Food 2001; 4: 79-83.

49. Pérez Y, Oyárzabal A, Mas R, Molina V, Jiménez S. Protective effect of D-002, a mixture of beeswax alcohols, against indomethacin-induced gastric ulcers and mechanism of action. J Nat Medicine 2013; 67: 182-189.

50. Leffler CT, Philippi AF, Leffler SG, Mosure JC, Kim PD. Glucosamine, chondroitin, and manganese ascorbate for degenerative joint disease of the knee or low back: a randomized, double-blind, placebo-controlled pilot study. Mil Med 1999; 164(2):85-91. 